\title{
LA FIGURA MINISTERIAL DE LOS RESPONSABLES LAICOS DE LOS GRUPOS, MOVIMIENTOS Y ASOCIACIONES ECLESIALES
}

\section{Graciela Otsu Navarrete}

os laicos que dirigen comunidades eclesiales de tipo asociativo, como
Mos grupos, movimientos y asociaciones, constituyen una figura ministerial que se está difundiendo cada vez más y que está tomando mayor fuerza, junto con el florecer de nuevas asociaciones laicales. El rol de estos laicos, se va haciendo cada vez más importante y estratégico para mantener la comunión de los grupos que dirigen con la Iglesia Universal y local por medio de sus legítimos pastores.

La presente reflexión teológico-pastoral no pretende abarcar todos los matices de la compleja cuestión, sino solollamar la atención sobre esta figura ministerial y evidenciar, así, algunos elementos importantes para perfilar su identidad y delimitar sus funciones y rolen la Iglesia.

\section{Una nueva época asociativa de los fieles laicos}

\section{El fenómeno delos movimientos y las nuevas comunidades eclesiales}

El fenómeno de los grupos, movimientos y asociaciones eclesiales se remonta al (capostolado asociadon,' 'que ha ido tomando, en los últimos tiempos, una 
fisonomía muy variada. ${ }^{2}$ Las asociaciones de fieles laicos no son una novedad en la historia de la Iglesia, que, ya desde antaño, ha visto florecer diversas formas asociativas con diferentes objetivos, como las confraternidades, las congregaciones marianas, las terceras órdenes, los diversos sodalicios y las cofradías. ${ }^{2}$ Muchas de ellas han sido creadas por iniciativa de los laicos; $y$ otras, como la Acción Católica, por iniciativa de la jerarquía.' Es notable cómo este fenómeno ha experimentado en los tiempos modemos un singular impulso con el surgimiento de múltiples formas asociativas, al punto que se puede hablar de unna nueva época asociativa de los fieles laicosn. Se trata de asociaciones nuevas, con fisonomias y finalidades específicas y sumamente diferenciadas unas de otras, tanto en su uconfiguración externa, en los caminos y métodos educativos» como en los ucampos operativos». No obstante, la diversidad de fines que persiguen, ya sea apostólico, de caridad, de evangelización o de santificación,' todas ellas coinciden en el único objetivo de participar responsablemente en la vida y misión de la Iglesia:" "Cada movimiento difiere del otro, pero todos están unidos por la misma comunión y por la misma misións."

Su existencia no solo se justifica, sino que se exige por diversos motivos: por la naturaleza social de la persona humana o por la necesidad de una incidencia cultural eficaz, posible solo a través de la acción de un sujeto social. ${ }^{10}$ Sin embargo, el motivo profundo es de orden eclesiológico, en cuanto el (apostolado asociado [...] es un signo de la comunión y de la unidad de la Iglesia en Cristom, "Esto significa, con palabras de Juan Pablo II, que wen el plano sobrenatural, la tendencia de los hombres a asociarse se enriquece y se eleva al nivel de la comunión fraterna en Cristo [...] que dice: "donde están dos o tres reunidos en mi nombre, allí estoy yo en medio de ellos" (Mt 18, 20)"), ${ }^{\text {is }}$ 
Para Juan Pablo II, los movimientos y las nuevas comunidades eclesiales, "comunidades cristianas vivas", como él las designa, son la urespuesta providenciab suscitada por el Espíritu Sarto al dramático reto lanzado por la ucultura secularizante» que domina hoy el mundo y que fomenta y reclama modelos de vida sin Dios, ya que su misión la desarrollan, principalmente, testimoniando el Evangelio en la sociedad. Por medio de ellos, la Iglesia puede tocar todos los grupos humanos y los diversos aspectos de la vida. ${ }^{13}$

Queriendo poner un poco de claridad en este panorama, me parece interesante la descripción simplificada y general que de estas agrupaciones hace la Conferencia Episcopal Italiana en la nota pastoral Criteri dei ecolesialità, teniendo siempre presente, sin embargo, las limitaciones de tal intento, sean terminológicas (existen otros términos no considerados, tales como ucomunidad" o usociedad») o de contenida (es mejor fijarse en la sustancía de las cosas antes que en el nombre), ya que en esta materia no se dan realidades rigidas y fijas,

Según la nota pastoral, la asociación se caracteriza por los siguientes aspectos: una estructura orgánica e institucional definida en un estatuto; adhesión formal de los miembros, por la condivisión de los objetivos y de los compromisos estaturarios; estabilidad y autonomia (relativa) de la asociación en cuanto institución, más allá del variar de los miembros; atribución de los cargos asociativos en base a criterios formales preestablecidos por el estatuto. A su vez, el movimiento se caracteriza, en general, por algunas ideas de fucrza y un espíritu común que hacen de elementos vinculantes más que estructuras institucionales. Frecuentemente, el movimiento se inicia alrededor de la figura y por la propuesta de un líder; mảs que con un estatuto se identifica con una doctrina y con una praxis que los caracteriza 
fuertemente y que tiende a ser una espiritualidad; la adhesión no es formal, sino vital: el movimiento existe por la adhesión vital continuamente renovada delos miembros sin inscripciones o carnés.

El grupo, generalmente, presenta estas características: cierta espontaneidad de adhesión y de permanencia por parte de los miembros; homogeneidad, también afectiva; gran libertad de autoconfiguración en cuanto a objetivos, estructura y actividad del grupo: una tendencia a la nouniformidad entre grupo y grupo; dimensiones relativamente reducidas y difusión más bien limitada; a veces, sobre todo si se trata de grapos de espiritualidad, determinada referencia común a una figura o a un valor idénticos, "Dentro de estas comunidades, tiene un papel fundamental la figura del responsable o los responsables.

\subsection{Los animadores de los grupos, movimientos y asociaciones eclesiales: identidad y funciones}

El sujeto ordinariamente responsable de la conducción de los grupos, movimientos o asociaciones, particularmente de aquellos laicales, por el mismo hecho de ser de laicos, debe ser obligatoriamente un laico. ${ }^{15}$ A modo ejemplar, según los estatutos del mavimiento Focolar, esta persona ues y será siempre una mujer laicay como presidenta, ayudada por un consejo; ${ }^{\text {it }}$ en el movimiento de Renovación en el Espíritu, los dirigentes son indistintamente hombres y mujeres que dependen de responsables a escala nacional y local, en L'Èquipes Notre-Dame, movimiento laical de parejas, son ellas mismas las que animan, en modo rotativo, lèquipe. Existe siempre una pareja que hace de enlace con los responsables de la ciudad, sector, región o superregión; y los responsables superregionales dan vida a un colegio, junto con un equipo 
internacional responsable que asegura la coordinación del movimienta. ${ }^{\text {it }}$ Las formas de organización pueden variar, pero se trata siempre de un equipo de responsables encabezado, generalmente, por alguien que posea una responsabilidad especial dentro de él.

La función del responsable o responsables laicos de toda comunidad cristiana, en líneas generales, se desarrolla en dos direcciones: al interior del grupo, donde tiene la función de la animación y promoción de la vida cristiana; y en relación con el contexto eclesial, donde tiene la función de ser un agente de enlace eclesial o de comunión con el obispo y con la Iglesia toda, local y universal. La primera función deriva de la naturaleza misma de toda comunidad cristiana, que existe para edificar el Reino, por lo que será tarea principal del responsable westimular, coordinar, y orientar los dones y carismas" de sus miembros para la edificación y misión de la Iglesia. La segunda función se fundamenta en causas eclesiológicas. Si estas comunidades no pretenden ser comunidades en sí mismas (sociológicas), sino una parte del único Pueblo de Dios y del única Cuerpo de Cristo, deben insertarse en el único organismo de la Iglesia y sentirse parte de ella. Este vínculo viene garantizado mediante la comunión con el Obispo (o con su representante) y, mediante él, con la Iglesia local y universal. En esta perspectiva, la autoridad que el responsable ejerce, en un cierto sentido, en el equipo animador y en la comunidad debe estar en función de la creación de este vínculo. ${ }^{19}$

La responsabilidad específica del animador varia según la dimensión de la comunidad (200,50,10 personas), según sus estructuraciones internas y objetivos concretos, Sin ernbargo, es posible describir el papel del animador en Ineas generales; para ello, sigo fundamentalmente a Nicholas Rieman, que se ha interesado particularmente en el caso. ${ }^{20}$ 
La responsabilidad especial del animador, generalmente compartida con otros miembros competentes del grupo que forman un equipo de responsables, está en el crecimiento cristiano de la comunidad y de sus miembros, es decir, en el crecimiento cuantitativo, pero sobre todo cualitativo, de la comunidad ctistiana. Se trata, sobre todo, de favorecer el crecimiento de la vida cristiana personal y comunitaria en la fidelidad al Espíritu Santo y a la Iglesia. La misma dinámica interior de la vida cristiana conlleva, luego, el impulso misionero de hacer partícipes a otros de la propia experiencia cristiana. Este impulso implica diversas responsabilidades:

- Custodiar que, en la comunidad, la Palabra de Dios sea transmitida según la interpretación y la enseñanza de la Iglesia (ortodoxia de la fe).

- Asegurar los servicios litúrgicos necesarios según las circunstancias.

- Promover una verdadera comunión de vida humana y de fe entre los miembros de la comunidad.

- Mantener los vínculos de fe y de caridad con el resto del Cuerpo de Cristo, tarea muy importante que se traduce en una voluntad de permanecer en comunión con el Obispo (o su representante) y, por medio de él, con la Iglesia local y universal: «e ello deriva que en los ámbitos de la doctrina y de la disciplina eclesial, es el animador quien, en el cuadro de la comunidad, tiene la responsabilidad últimav. Asimismo, asegurar vínculos estrechos con las otras comunidades cristianas de la diócesis o de la región y, de modo especial, con la partoquia y su responsable, el párroco; fomentar contactos ecuménicos, la comprensión recíproca y la colaboración con las comunidades cristianas separadas; y ayudar a la comunidad a desarrollar la conciencia de que forma parte de la Iglesia local y univetsal, en otras palabras, deșarrollar el sentido de Iglesia, manteniéndose en comunicación y colaboración con 
todo el Pueblo de Dios. Esto incluye la recepción y actuación de las directivas pontificias, de los Sínodos de los Obispos y de las Conferencias Épiscopales. - Orientar las fuerzas de la comunidad hacia el servicio de la evangelización en sus diversas formas y, sobre todo, hacia el testimonio de la vida cristiana.

- "Orientar a la comunidad cristiana hacia su total integración en la vida y al servicio de la comunidad humana en todos los nivelesy comprometiéndose en las acciones en favor de la promoción y liberación humana, de la justicia, del respeto de la dignidad humana y la participación en la transformación de las realidades temporales, todo esto como campo propio de los laicos en la actividad evangelizadora.

Evidentemente, aun cuando la responsabilidad de estas tareas recae en el animador-responsable, no deben ser todas realizadas personalmente por él, quien deberá, más bien, favorecer la participación, corresponsabilidad y formación de todos, sobre todo de aquellos que ya conforman el equipo de animación según su particular carisma. ${ }^{21}$

Los nuevos movimientos, grupos y asociaciones religiosos católicos, y el rol de sus responsables en su seno han surgido en virtud de la nueva perspectiva eclesiológica de comunión del concilio Vaticano II y se han ido configurando sucesivamente, con normativas y orientaciones del magisterio postconciliar.

\section{La visión del magisterió conciliar y postconciliar sobre los responsables laicos de comunidades eclesiales}

La atención del magisterio conciliar y postconciliar no se centra tanto en la figura del laico como animador de la comunidad, sino en las formas asociativas 
de apostolado de los laicos. Sin embargo, no faltan afirmaciones importantes sobre este tipo de ministerialidad laical.

\subsection{El concilio Vaticano II}

Ante todo, es importante recordar que antes del Vaticano II una asociación era reconocida como tal solo si era erigida o aprobada por la jerarquía, lo cual limitaba grandemente la iniciativa de los laicos. ${ }^{2}$ El concilio hace importantes afirmaciones acerca del apostolado asociado, las mismas que constituyen una verdadera novedad, no solo por lo que se refiere a la afirmación del derecho de libre asociación de los laicos, sino también porque legitima el rol de sus responsables: «Guardando la relación debida con la autoridad eclesiástica, los laicos tienen derecho a fundar asociaciones, a dirigirlas y a afiliarse a las ya fundadasm. ${ }^{23}$

Este derecho de libre asociación no responde a una concesión de la jerarquía, sino que se funda en el estatuto bautismal del cristiano laico, por medio de dicho estatuto tiene el derecho-deber de participar en la comunión y misión de la Iglesia. ${ }^{4}$ En los pastores está el reconocer y estimular dicha participación, animar y sostener sus iniciativas y darles la posibilidad y libertad de actuación. ${ }^{2 s}$

El concilio reconoce cómo estas obras apostólicas instituidas por los laicos y «regidas por su prudente juicion son, en algunas circunstancias, una valiosa ayuda para el mejor cumplimiento de la misión. La única condición exigida es guardar la debida comunión con los pastores y, a través de ellos, mantener la unidad en la Iglesia, ${ }^{\infty}$ ya que esta es comunión, pero, por divina institución, es también consritucionalmente jerárquica; por ello, el apostolado de los laicos está evidentemente subordinado a la jerarquía." Este vínculo 
con la jerarquia admite diversas gradaciones o modos de relación de acuerdo a las diversas formas y fines del apostolado mismo de los laicos, que determinan también el grado de responsabilidad que la jerarquía asume frente a estas agrupaciones de laicos. Esta se explica, a su vez, en una determinada forma de aprobación o reconocimiento que va desde lazos eclesiales que se podrían considerar implícitos, como los de aquellos laicos que participan en los grupos o actividades apostólicas de la parroquia o de la diócesis, " hasta las asociaciones que son reconocidas explícitamente y de modos diversos por la autoridad eclesiástica," así como aquellas elegidas y promovidas por la misma, particularmente las «obmas apostólicas que tienden inmediatamente a un fin espirituals. ${ }^{30}$

\subsection{La Evangelii nuntiandi (1975)}

La Evangelii nuntiandi de Pablo VI da un paso adelante con respecto al concilio, que se resiente todavía de la distinción de aministerion a los laicos. Por lo que se refiere al servicio de los responsables de los movimientos y nuevas comunidades eclesiales, la Evangelii nwntiandi ve en ellos, entre otros, un verdadero ministerio eclesial, valioso tanto para la implantación de la Iglesia como para su misión: "Tales ministerios, nuevos en apariencia, pero muy vinculados a experiencias vividas por la Iglesia a lo largo de su existencia _ _ [...] jefes de pequeñas comunidades, responsables - de los movimientos apostólicos uotros responsables son preciosos para la implantación, la vida y el crecimiento de la Iglesia y para su capacidad de irradiarse en torno a ella y hacia los que estản lejosw." Esta afirmación de avanzada, a solo diez años del concilio Vaticano II, ha contribuido, sin duda, al desarrollo de la ministerialidad laical en sus diversos ámbitos. 


\section{3, El Código de Derecho Canónico (1983)}

El nuevo Código de Derecho Canónico es el documento que proporciona seguramente orientaciones más precisas sobre el derecho de asociación de los fieles laicos y sobre los responsables laicos de la comunidad. Esta atención particular da a entender la importancia que tiene este ministerio para la vida de la Iglesia.

En cuanto a los responsables de las comunidades asociativas, el nuevo código considera dos tipos de asociaciones: públicas y privadas; y el responsable de ambas es llamado iptesidenten (moderatorem), ${ }^{12}$ que puede ser un clérigo, un laico" o un religioso o religiosa."

Las asociaciones públicas son aquellas etigidas por la autoridad eclesiástica competente (Santa Sede, Conferencia Episcopal u Obispo), según sean los alcances de la asociación a nivel universal o internacional, nacional o diocesano. "Estas, habiendo recibido una misión para los fines que se proponen alcanzar, actúan en nombre de la Iglesia., Las asociaciones privadas son reuniones espontáneas de los fieles, mediante un acuerdo privado," para conseguir un fin espiritual, apostólica o caritativo según lo dispuesto en el código." Para ser reconocidas en la Iglesia, es necesario que la autoridad competente examine sus estatutos, ${ }^{\text {a }}$ sin embargo, la aprobación de estos no cambia la naturaleza privada de la asociación."

Ambos tipos de asociación, aun las privadas que gozan de autonomia," están sujetas a la vigilancia de la autoridad eclesiástica, así como al gobierno de la misma autoridad, de modo que sea conservada la integridad de la fe y de las costumbres y evitar que se cometan abusos en materia de disciplina eclesiástica ${ }^{\circ}$

El presidente de las asociaciones públicas de fieles puede ser elegido por los miembros de la asociación y, luego, confirmado por la autoridad 
eclesiástica; ser presentado (él a los candidatos) por la asociación y nombrado por la autoridad eclesiástica; ser nombrado por la autotidad eclesiástica sin ninguna presentación."

Los presidentes de las asociaciones privadas de fieles no necesitan ser confirmados por la autoridad eclesiástica. Estas asociaciones son dirigidas y presididas por fieles que designan libremente el moderador y los oficiales según lo dispuesto en los estatutos. ${ }^{\text {"5 }}$ Pueden también, si lo desean, designar libremente entre los sacerdotes de la diócesis un consejero espititual, el cual debe ser confirmado por el Ordinario del lugar. ${ }^{40}$

Otra importante novedad del nuevo código son las normas especiales para los dirigentes de las asociaciones de laicos que se pueden considerar como importantes tareas oxientadas hacia la comunión y la formación que estos deben tener muy presentes: «Quienes presiden asociaciones de laicos, [...] deben cuidar de que su asociación colabore con las otras asociaciones de fieles, donde sea conveniente, $y$ de que presten de buen grado ayuda a las distintas obras cristianas, sobre todo a las que existen en el mismo territorio" " "Los presidentes de las asociaciones de laicos deben cuidar de quelos miembros de su asociación se formen debidamente para el ejercicio del apostolado propio de los laicoss."

Con relación a los movimientos eclesiales, es importante añadir que esta novedad introducida por el Espíritu no ha encontrado aún una precisa colocación en el Código de Derecho Canónico: no está previsto todavía para los movimientos eclesiales un estatuto canónico. Estos son aprobados como asociaciones de fieles, aunque las normas previstas no resultan suficientemente adaptadas a la realidad misma de estos movimientos." 


\subsection{La Cbristifideles laici (1988)}

La Christifideles laici de Juan Pablo II toma en consideración las «formas agregativas de participación,${ }^{50}$ pero no hace ninguna afirmación particular sobre el responsable laico de estas comunidades. Insiste mucho en la necesidad de que estas asociaciones sean verdaderamente signos que manifiesten la comunión eclesial dentro y fuera del ámbito de las diversas formas asociativas (de aquí la exigencia de criterios de discernimiento acerca de la autenticidad eclesial de esas formas asociativas o de «criterios de eclesialidad", de los cuales se tratará más adelante). ${ }^{51}$ En efecto, el derecho de asociación de los laicos, que incluye el derecho a la dirección de estas mismas asociaciones, debe ser ejercido «siempre y sólo en comunión de la Iglesias. Se puede decir, entonces, por extensión o por inclusión, que el derecho no solo de asociarse, sino también de dirigir estas asociaciones wes algo esencialmente relativo a la vida de comunión y a la misión de la misma Iglesian. ${ }^{52}$ La comunión y la misión se presentan como el único horizonte posible del ejercicio de tal ministerialidad laical.

\subsection{Redemptoris missio (1990)}

La Redemptoris missio de Juan Pablo II no habla directamente de los laicos responsables de las comunidades eclesiales asociativas; hace simplemente referencia a ellos de un modo genérico. Al hablar de la obra de los catequistas y la variedad de ministerios, menciona, entre otros, a los responsables de comunidades eclesiales de base y a los dirigentes de los diversos grupos y asociaciones apostólicas."

Sin embargo, menciona la importancia de la acción misionera de los laicos, no solo en el campo secular que les es propio, sino también en el 
ejercicio de diversos tipos de servicios, funciones, ministerios y formas de animación de la vida cristiana dentro de la Iglesia. Resalta la importancia de las formas tanto personales como asociativas de apostolado de los laicos, particularmente para anunciar el Evangelio en aquellos ambientes adonde solo ellos pueden llegar, Recomienda su difusión y exhorta para valerse de ellos con la finalidad de revigorizar la vida cristiana, sobre todo de los jóvenes, a la vez que invita a las varias formas asociativas de laicos a dar su aportación a la misión "ad gentes» y en las iglesias locales."

Respecto de los nuevos movimientos, el Papa da una indicación importante: pone dos condiciones para que estos sean un verdadero don de Dios para la misión específica ad gentes y para la Nueva Evangelización. Se trata de una actitud de recíproca acogida: inserción humilde en la vida de la Iglesia local, de parte de los movimientos, y acogida, de parte de los pastores en Las estructuras de la Iglesia diocesana y parroquial, ${ }^{\text {s5 }}$

De cuanto se ha expuesto se puede decit que el servicio de los laicos (particularmente en el campo de la dirección-animación de los grupos, movimientos $\mathrm{y}$ asociaciones) es un hecho y una necesidad reconocidos por el magisterio de la Iglesia que responde, además, a la recuperación de una auténtica conciencia eclesial por parte de los laicos.

\section{Los responsables laicos de comunidades eclesiales al interior de la Iglesia ministerial}

El concilio Vaticano II, basándose en el fundamento bíblico, explica el ministerio de la Iglesia como participación en el utriple oficio de Cristo»: sacerdote, profeta y rey. ${ }^{56}$ Esta trilogía ofrece una perspectiva esencial de los ministerios en la Iglesia basada en el triple munus, conformado tanto por 
la jerarquía como por los laicos, quienes cumplen, ken la Iglesia y en el mando, la parte que les corresponde en la misión de todo el pueblo de Dios». ${ }^{57}$ Esta misma trilogía de funciones ha sido seguida en el magisterio postconciliar $1^{59}$ por el Código de Derecho Canónica y y por muchos autores contemporáneos para explicar la ministerialidad de la Iglesia." En esta perspectiva deductiva, la presidencia de la comunidad ha sido entendida en estrecha relación con la realidad sacerdotal de Cristo (dimensión litúrgica), muchas veces en detrimento de la dimensión pastoral del mismo Cristo y de la Iglesia, Esta implantación ha dado a luz algunas visiones de corte clerocéntrico, como la de Brandolini, quien describe la acción pastoral alrededor de tres centros; el ministerio de la palabra, el ministerio del sacerdocio y el ministerio de la caridad, que incluye el servicio de la caridad y el servicio a la «comuniónmen el interior de la comunidad eclesial mediante la animación por parte de aquellos a quienes compete organizar las iniciativas y los servicios con los que se edifica la Iglesia, refiriéndose, particularmente, por no decir exclusivamente, a la jerarquia. ${ }^{61}$ En efecto, una concepción demasiado clerical de la Iglesia podtía atribuir al laico una posición pasiva en la dirección de la comunidad eclesial; es decir, considerar al laico como objeto (de parte de los clérigos, de la realeza), cuando el cristiano laico es, a la vez, por el bautismo y por la confirmación, también sujeto de acción pastoral.

En el caso de la clásica trilogía, el servicio de los laicos responsables de grupos, asociaciones y movimientos que desarrollan un servicio de animación y coordinación de comunidades eclesiales vendría a colocarse dentro de la ministerialidad real como un servicio de dirección de la comunidad para conducir a los hermanos al Reino de Dios. Sin embargo, no pocos autores advierten que la triple repartición, tradicionalmente aplicada a la ministerialidad eclesial, es insuficiente y poco funcional, especialmente cuando se trata de 
fijar los contenidos y los términos de cada función. ${ }^{62}$ Esta observación es particularmente válida para la colocación de la ministerialidad de los responsables laicos de comunidades dentro de esta trilogia. ${ }^{65}$ A esta dificultad, Mario Midali, notable pastoralista italiano, añade otra con relación a la dificultad de la teología práctica de redactar una catalogación capaz de acoger, de modo orgánico, formas nuevas de expresión de la acción eclesial que surgen como respuesta a nuevas exigencias reclamadas por la necesaria transformación histórica de la Iglesia (como es el caso del servicio ministerial de los responsables de las nuevas comunidades: grupos, movimientos y asociaciones); por ello, este autor hace presente la necesidad de una catalogación «abierta»."

Teniendo presente estas observaciones, intento esbozar una colocación posible para este tipo de ministerialidad sirviéndome de algunas aportaciones al tema.

Uno de los autores que toca directamente el tema de la ministerialidad odegética es Alfredo Pouilly, quien, hablando de la ministerialidad de los laicos, identifica la función real o «acción de servicio» de la Iglesia con la pastoral odegética e incluye en ella tanto el servicio de la caridad como el servicio de pastores. En este último servicio, los laicos juegan un papel importante como animadores de la comunidad, asesores y coordinadores de pastoral, así como en los oficios eclesiásticos. Él entiende por pastoral odegética «todas las acciones que tienen como finalidad conducir al Pueblo de Dios, indicándole las exigencias morales de la fe en todos lo campos de vida - privada, familiar, profesional, civica..., $y$ hacer efectiva la pastoral orgánicas, Aparentemente, percibe una cierta ambigüedad en el término «odegética» aplicado a la doble realidad (servicio de caridad y servicio de pastores) cuando añade: «Se han buscado varios nombres para designar 
este tercer aspecto de la pastoral, pero ninguno parece adecuado, Se podría llamar también - si el término no sufriese de un cierto descrédito"pastoral moral": se ocupa en efecto de las relaciones humanas dentro del Pueblo de Diosm. ${ }^{5}$ En esta perspectiva, la insistencia en mantener unidos estos dos aspectos de la praxis eclesial no permite focalizar el objetivo fundamentalmente comunional de la ministerialidad odegética.

Otra clasificación interesante viene presentada por Dionisio Borobio, quien propone una división de toda la acción eclesial en cuatro dimensiones a fin de especificar mejor los diversos aspectos de la misión-ministerialidad de la Iglesia: la martyria, orden de la palabra-testimonio; la leiturgia, orden del culto; la koinonia, servicio de la dirección de la comunidad para la comunión; y la diakonia, servicio de la caridad. "Tales dimensiones tradicionalmente se resumen en la ministerialidad real. Esta distinción cuadridimensional de los ministerios eclesiales, aparte de funcional, representa una apertura que permite individualizar y acoger el servicio de los laicos responsables de diversos tipos de comunidades eclesiales en kEl servicio de la dirección-comunión o koinonía, que tiene por función el servicio de la representación y la unidad entre los miembros y las comunidades, y engloba los ministerios de la presidencia, los responsables de comunidades y de grupos, los miembros activos en los consejos de dirección de la comunidad quienes, de una manera orgánica y diferenciada, participan del mismo centro ministeriabs. ${ }^{37}$

La función de los responsables de los grupos, movimientos y asociaciones eclesiales podria encuadrarse, entonces, en el ámbito de la ministerialidad odegética de la Iglesia con la siguiente especificación terminológica: si bien el término «ministerialidad», en sentido genêrico, se refiere a la vocación al servicio de toda la Iglesia, en un sentido más específico y siguiendo una distinción muy difundida hoy, podriamos llamar uministerion a un carisma 
reconocido y ejercido de modo más o menos estable a favor de la comunión y misión de la Iglesia en sus diversos ámbitos (profético, sacerdotal y real), "Io que responde a las exigencias permanentes de su misión.

Con ministerialidad «odegéticas de los laicos (sobre la base etimológica del término), me refiero a aquellos ministerios eclesiales que pueden desempeñar los laicos que se colocan en el ámbito de la koinonia y que tienen la función de indicar el camino (=odòs) animando y coordinando de modo global las diversas dimensiones de la pastoral (profética, litúrgica y diaconal) en armonia y colaboración con el ministerio ordenado, de modo que se mantenga la comunión y la unidad en la Iglesia. Este se configura como un servicio de animación y de dirección de las comunidades eclesiales que incluye, fundamentalmente, dos tipos ministeriales: aquellos responsables de comunidad en ausencia de ministros ordenados, llamados por eso de «suplencias, ya prevista por el Vaticano $\Pi^{\star s}$ - que presenta una problemática particular que no toco en estas páginas - y aquellos que ejercen los laicos de hecho, sea aquellos propios de los laicos, aunque no exclusivos ${ }^{n}$ (como los animadores pastorales, los guias de los diversos tipos de grupos, llámense comunidades eclesiales de base o simplemente grupos partoquiales, asociaciones y movimientos laicales), sea aquellos oficios eclesiásticos por los cuales los fieles laicos participan en los organismos de decisión (como los consejos pastorales, consejos de asuntos económicos, sínodos diocesanos, concilios particulares, etc.).

\section{La parroquia y el pártoco, las asociaciones \\ y sus responsables: algunas diferencias esenciales}

Este nuevo tipo de ministerialidad de los laicos, ya sea con responsabilidad personal o de suplencia, tiende, por su propia naturaleza, a entrar en conflicto 
con la responsabilidad pastoral propia del ministerio ordenado, sobre todo en el campo de la autoridad; por ello, será necesario considerar algunas diferencias esenciales útiles para delimitar el campo de actuación de la ministerialidad odegética de los laicos que dirigen comunidades eclesiales.

\subsection{El concepto de «comunidads}

Cuando se habla de ministerialidad odegética de los laicos o de los ministerios de dirección-animación de comunidades que ejercen los laicos, debemos establecer a qué comunidades nos referimos. En realidad, la diferenciación que hacemos hoy entre Iglesia y comunidad no figura en el Nuevo Testamento, donde aparece solamente el término «Ekklesia», que designa, a un mismo tiempo, la asamblea litúrgica (reunida para escuchar la Palabra y celebrar la Eucaristía), la comunidad de los creyentes (localizada en un determinado lugar) y la Iglesia Universal. Cada una de las comunidades está llamada a manifestar en sí misma, en comunión de fe y en un modo visible la realidad del ser de la Ekkelesia en comunión con las demás Iglesias. En este sentido, las diferencias entre Iglesia y comunidad se podrían considerar más de carácter sociológico e institucional que de contenido teológico y biblica." La diferencia se encuentra más delineada en la reflexión que algunos canonistas han desarrollado en perspectiva pastoral.

Según Coccopalmerio, ken la estructura de las Iglesia hay dos tipos de sujeto comunitario: la asociación y la parroquiar ${ }^{22} \mathrm{o}$, si se desea, según Borras, dos tipos de comunidades: «comunidades jerárquicas» y "comunidades asociativas»." Entre la partoquia $y$ las asociaciones, hay algunas diferencias esenciales. Las diferencias se pueden determinar en torno a la finalidad que persiguen, en los medios de la gracia a disposicióny 
en los modos de participación de los bautizados en la única misión de la Iglesia.

En cuanto a la finalidad quepersiguen, la parroquia, como comunidad jerárquica, es para todos y para todo, mientras las comunidades asociativas persiguen fines particulares que responden a las expectativas exclusivas de un grupo. En este último tipo se encuadran los grupos, movimientos y asociaciones. Este carácter particular les impide ser «para todos y para todom: ${ }^{\text {"4 }}$ son solo una parte de la totalidad de la Iglesia, mientras en la Iglesia local, diócesis o parroquia (célula dela diócesis), se encuentra presente, se manifiesta y actúa la Iglesia Universal. ${ }^{\text {t5 }}$ Por eso, aunque es claro que no es toda la Iglesia, Ia parroquia ocupa un lugar preeminente para el sentido de pertenencia de los fieles a la Iglesia. Ia Eucaristía celebrada en la comunidad es el lugar en el que la Iglesia se muestra tal como es en la diversidad de carismas y ministerios.

La parroquia (Iglesia particular) cuenta con todos los medios de la gracia necesarios: sacramentos, ministerios, instituciones, etc.; se trata de la Iglesia localizada en un lugar determinado, mientras que en los grupos y asociaciones no viene necesariamente asegurado lo esencial para la vida cristiana. ${ }^{76}$ Todos los fieles en ambos tipos de comunidad participan en la única misión de la Iglesia, pero las comunidades jerárquicas lo hacen con un carácter global e integral. "La Iglesia local es el sujeto eclesial directamente responsable de la comunión y misión de la Iglesia." Por eso, debe organizarse el modo de abrazar la acción pastoral de forma integral (martyria, leiturgia, koinoria, diakonia), mientras los grupos asociativos organizarán sus actividades según sus propios principios y finalidades particulares, que, por lo general, se pueden ubicar en una de estas vertientes. De aquí que las asociaciones y movimientos deban tratar de insertarse plenamente en la Iglesia particular al servicio de la comunión y de la misión de toda la Iglesia. 
En cuanto al modo de participación de los bautizados en las comunidades asociativas, puede calificarse como democrático; por el contrario, en las comunidades jerârquicas todos los fieles deben hacer necesariamente referencia a la autoridad pastoral, al pàrroco o al obispo, quienes les hacen presente y les ponen en sintonia continua con la catolicidad y la apostolicidad de la Iglesia." Esto último no se puede asegurar automáticamente de los grupos, movimientos y asociaciones, en los que está por verificarse la presencia de los «criterios de eclesialidad» que los gamantizan como verdaderas comunidades eclesiales." Las comunidades asociativas reflejan valores eclesiales, pero no todos, por lo tanto, se pueden llamar Iglesia local (falta la relación directa con el obispo y, por lo tanto, con la Eucaristía). La I glesia local no se puede concebir sin referencia al episcopado, por eso, las comunidades eclesiales en la Iglesia Católica deben buscar relacionarse con el obispo, garantía de comunión eclesial." De otro modo, corren el riesgo de crear Iglesias paralelas, desconectadas de la Iglesia Universal. En este sentido, respecto de la ministerialidad odegetica, es importante notar que una comunidad que se quieta llamar verdaderamente eclesial no solo no puede dejar de lado el ministerio ordenado, sino que su presencia es indispensable y no reemplazable por el ministerio del laico que la anima o coordina. Más allá de una limitación, este hecho pone en evidencia la misión diferenciada de los miembros del Pueblo de Dios, misión que no puede desconocer niveles de participación, en este caso, sobre la base sacramental del ministerio y que se resuelve en la complementariedad de funciones, servicios y ministerios al servicio de la edificación de la Iglesia, lo que implica, por una parte, evitar toda sustitución o confusión de roles; $y$, por otra, el respeto del principio de subsidiariedad. 


\subsection{Los responsables de las comunidades asociativas, y los párrocos}

En lo que se refiere a la diferencia entre los que presiden las comunidades asociativas y las parroquias, la comunidad parroquial es competencia del párroco, quien, en nombre del obispo, preside la comunidad eclesial, caracterizada por la multiplicidad de los carismas suscitados por el Espíritu Santo para la edificación de la Iglesia. Tarea del ministerio sacerdotal es, justamente, el discernimiento de tales carismas.

Otro será el caso de los grupos, asociaciones o movimientos, en los que los laicos dirigen comunidades con un particular carisma y lo hacen con una responsabilidad propia. Se trata de un ministerio propio de los laicos en el que ejercen, ellos también, su pastoralidad, basada en el sacramento del bautismo y la confirmación, los que, por otra parte, no los habilitan para ser pastores de la Iglesia local.

Entre los que dirigen estos dos tipos de comunidades se puede señalar una diferencia esencial: en la asociación, todos los miembros tienen una posición jerárquicamente igual; el responsable o el presidente tiene, por lo tanto, una posición jerárquica igual a la de cualquier otro miembro y cumple una función que le viene desde abajo: es primus inter pares en la comunidad; mientras que en la parroquia, el que preside, o sea el párroco, tiene una posición jerárquicamente superior a la de los demás miembros de la comunidad por el sacramento del orden y por el nombramiento recibido del obispo, "que lo habilita para animar y guiar a la comunidad con la

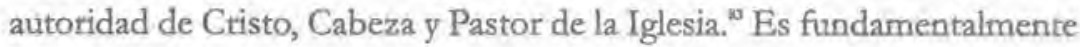
un servicio esencial a la unidad de la Iglesia, distinto de los demás servicios y al servicio de ellos." Corresponde al ministerio sacerdotal, por un lado, y sobre todo, garantizar la apostolicidad y la comunionalidad de la comunidad 
eclesial; y, por otro, representar a la Iglesia, no como un simple delegado de la comunidad, sino como su ministro y representante: $\langle\mathrm{El}$ sacerdote ministerial puede representat a la Iglesia porque representa a Cristom. ${ }^{15}$ Esta función no puede realizarla el cristiano laico sino en una cierta medida y nunca con la misma «significatividad y eficacia que el ministro ordenado»."

Podemos, entonces, concluir que tanto en las partoquias como en las comunidades asociativas, los laicos pueden ejercer ministerios odegéticos basados en los sacramentos de la iniciación cristiana, pero a título diferente. El ministerio del responsable de los grupos, movimientos y asociaciones ejercidos por los laicos se coloca en el ámbito de la corresponsabilidad laical, mientras otros ministerios odegéticos laicales, como la participación de los laicos en la cura pastoral de las parroquias, se consideran en el ámbito de la colaboración que algunos son llamados a ejercer, en nombre de la Iglesia, cuando son solicitados por la autoridad competente.

Creo que no es dificil convenir en que los ministerios odegéticos de los responsables laicos de comunidades ocupan un lugar verdaderamente delicado y estratégico en orden a la realización de la comunión eclesial, motivo por el que es importante determinar su real eclesialidad, es decir, ¿en qué condiciones estos responsables ejercen un verdadero ministerio eclesial?

\section{Criterios de eclesialidad}

El primer criterio para determinar si un ministerio odegético laical es eclesial es, sin duda, determinar sila comunidad a la que hace referencia es verdaderamente eclesial. El término «eclesialidad» es exigente: significa usaber pertenecer a la Iglesia y, más aún, saber "ser Iglesia" y tener el "sentido de Iglesia" "." En 
realidad, "criterios de eclesialidad" es una terminología asumida por la Iglesia Universal en la Christifideles laicin. ${ }^{\circ} 30$ en relación con cualquier agrupación de fieles laicos en la Iglesia, refiriéndose a los criterios de discernimiento y de reconocimiento según los que una asociación de fieles laicos puede considerarse una verdadera comunidad eclesial. El término «eclesialidad» tiene una connotación más bien teológica; se refiere a algunos valores fundamentales y, por lo tanto, irrenunciables de la ortodoxia y de la ortopraxis eclesial, propuestos a las nuevas realidades asociativas que surgen hoy en la Iglesia para ofrecerles un punto fijo de confrontación y de orientación, y referidos a los pastores como una ayuda, no solo para cl examen sino también para su acompañamiento."

Lamentablemente, estos criterios no siempre son tomados en consideración para una evaluación personal o comunitaria. A esto, contribuye el hecho de que en la aprobación diocesana o pontificia prevalecen los criterios canónicos de reconocimiento, ya que, según nuestro conocimiento, los critetios de eclesialidad no han sido formalizados hasta hoy en el Pontificio Consejo para los laicos o en otras instancias." Sin embargo, algunas conferencias episcopales, entre ellas la Conferencia Episcopal Peruana, "a través de sus comisiones episcopales ad hoc, se han preocupado por establecer algunos elementos para determinat la eclesialidad de las comunidades cristianas que surgen en su seno."

Prácucamente, toda comunidad cristiana, en sus diversos niveles (diócesis, parroquias, comunidades personales, de base, religiosas, y otros grupos), tendría que confrontarse con estos elementos que identifican una verdadera comunidad eclesial." Sin embargo, los criterios a los que se refiere la Christifideles laici tienen por destinatarios a las comunidades asociativas y no tanto a las jerárquicas, en las que estos valores vienen garantizados por 
la presencia y presidencia del ministerio ordenado, a excepción de aquellos criterios válidos explícitamente para los laicos con relación al carácter secular que les es propio y peculiar."

Según la Christijideles laicin. ${ }^{\circ}$ 30, una comunidad cristiana es eclesial o representa adecuadamente a la Iglesia si cuenta con los siguientes elementos: «L a primacía que se da a la vocación de cada cristiano a la santidad [...] como crecimiento hacia la plenitud de la vida cristiana y a la perfección en la caridady; «L a responsabilidad de confesar la fe católicay; «El testimonio de una comunión firme y convencida [...] con el Papa y con el obispo [...] y con las diversas formas asociadas de los fieles laicos en la Iglesiay; «La conformidad y la participación en el "fin apostólico de la Iglesia", que es "la evangelización y santificación de los hombres y la formación cristiana de su conciencia" [...] que les lleve a ser, cada vez más, sujetos de una nueva evangelizaciónw; «El comprometerse en una presencia en la sociedad humana [...] al servicio de La dignidad integral del hombres"; los " "frutos concretos" que acompañan la vida y las obras de las diversas formas asociadas", como comprobación de los criterios fundamentales citados. ${ }^{\text {. }}$

Ya que es solo en la perspectiva de la comunión y de la misión de la Iglesia que se comprenden los criterios de eclesialidad, prácticamente, en un cierto sentido, todos estos criterios confluyen en uno, sin el cual no es posible ni siguiera la voluntad de confrontarse con los criterios de eclesialidad. Se rrata de mantener la comunión con la Iglesia mediante el obispo o su representante y, en consecuencia, con las demás cornunidades eclesiales, principalmente con la parroquia y con las otras formas asociativas de los laicos. 


\subsection{La necesaria comunión con el obispo}

La comunión con los legítimos pastores garantiza la ortodoxia y la ortopraxis eclesial, pone en comunión con las demás formas asociativas y hace posible la necesaria sinergia de fuerzas en orden a la realización de la misión de la

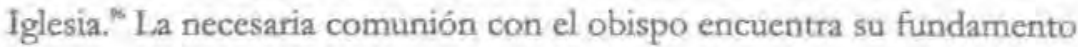
en la praxis de la Iglesia primitiva referida en el Nuevo Testamento por las Epistolas Paulinas, los Hechos de los Apóstoles, y los Padres de la Iglesia;" y es confirmada por la tradición eclesial, el concilia Vaticano II y, en general, el magisterio de la lglesia. Es más, se trata de una prerrogativa a la que los obispos no pueden ni deben renunciar por el bien mismo de las asociaciones laicales, como lo indica claramente la Christifideles laici:

Los pastores en la Iglesia no pueden renunciar al servicio de su autoridad, incluso ante posibles y comprensibles dificultades de algunas formas asociativas y ante el afianzamiento de otras nueyas, no sólo por el bien de la Iglesia, sino además por el bien de las mismas asociaciones laicales. Así, habmán de acompañar la labor de discernimiento con la guía y, sobre todo, con el estímulo a un crecimiento de las asociaciones de los fieles laicos en la comunión y misión de la Iglesia."

Es necesatio también afirmar, junto con Juan Pablo II, que la relación con la autoridad eclesiástica «implica una voluntad fundamental de armonía y de cooperación eclesialy" de parte de la asociación, lo que no impide su autonomia propia, sino que la pone en comunicación con el resto del cuerpo eclesial. ${ }^{10}$ 


\subsection{La reciproca acogida entre pastores y responsables de las comunidades asociativas}

Segun las indicaciones de la Redemptoris missio, esta voluntad de armonia y cooperación eclesial exige un movimiento de apertura y de recíproca acogida de parte de la autoridad eclesiástica y de las comunidades asociatívas. ${ }^{10}$ En palabras de Rieman, es necesario que la comunidad sceciba del Obispo la comunicación de sus preocupaciones, necesidades y directrices» y que "comparta con él sus propios deseos, logros, inspiraciones, recursos, e incluso sus quejas ${ }^{102}$ Como representantes del obispo, los párrocos se sitúan en una posición análoga. Esta relación depende en gran parte de los responsables de estas comunidades, sobre todo si se considera el estilo democrático de elección de los responsables de las comunidades asociativas, según el cual estos se constituyen en representantes del ser y del sentir del grupo que dirigen. Por lo tanto, son los primeros llamados a confrontarse con los criterios de eciesialidad y a orientar el grupo hacia la realización de estos. Esta tarea fundamental habla ya de la exigencia de una capacidad indispensable en el responsable: poseer el equilibrio suficiente para, a un mismo tiempo, salvaguardar la unidad con la Iglesia (también en el ámbito parroquial) respetando la autonomía del grupo que dirige. ${ }^{100}$

Marcandalli, reflexionando sobre un texto del cardenal Martini, resalta algunas de las muchas dificultades y peligros latentes en los nuevos movimientos eclesiales, ${ }^{\text {tot }}$ entre los que señala como el más importante y delicado la scelación entre estas nuevas realidades eclesiales y la Iglesia Locabs, en otras palabras, el problema de la comunión efectiva entre los movimientos y la Iglesia local, llámese diócesis o parroquia. Pasando del plano de las instituciones al plano personal, resalta el rol importantísimo 
que juegan los responsables de los movimientos. Más aún, en la opinión de Marcandalli, ula experiencia enseña que mucho (por no decir "casi todo") dependa del modo con el cual los responsables de los movimientos y los responsables de la Iglesia local se ponen los unos frente a los otrosm. ${ }^{\text {to }}$ Destacándola del conjunta de la comunidad eclesial (movimiento, asociación, grupo) se puede ver, en efecto, la importancia de la función del responsable o responsables en la comunión de todo el grupo con la Iglesia local.

\subsection{Mantener la comunión con la parroquia}

\section{y entre las diversas formas asociativas}

《Todos, pastores y fieles, estamos obligados a favorecery alimentar continuamente vínculos y relaciones fraternas de estima, cordialidad y colaboración entre las diversas formas asociativas de los laicos», ${ }^{1 m}$ deponiendo todo espiritu de antagonismo y de contienda y compitiendo, más bien, en la estima mutua. Esta recomendación de la Christifídeles laici es válida, especialmente, para los responsables laicos de las comunidades, y exige de estos un auténtico espítitu eclesial y de comunión que los haga conscientes y responsables, en primera persona, de salvaguardar la realidad diversificada y, a la vez, unitaria de la Iglesia y que les permita anteponer los intereses de la Iglesia a los intereses particularistas del grupo: ${ }^{i 0}$ "Ser responsables del don de la comunión significa, antes que nada, estar decididos a vencer toda tentación de división y de contraposición que introduzca insidias en la vida y el empeño apostólico de los cristianosm.

Por otro lado, para mantener la comunión entre la comunidad parroquial y las asociaciones, y entre estas áltimas es esencial el rol que juega la parroquia. La nueva perspectiva eclesial que se viene configurando 
postula una nueva imagen de la parroquia como ecentro de coordinación y animación de comunidades, de grupos y movimientosm." Por lo tanto, es importante la política de la parroquia con respecto a estas asociaciones y a sus responsables, es decir, es necesario repensar el modo de colaboración que se puede prever de estos grupos en la pastoral de conjunto, y el lugar que se da a los responsables laicos de grupos, movimientos y asociaciones en las estructuras de participación de los fieles en las parroquias, como, por ejemplo, en los consejos pastorales, como aconseja el concilio Vaticano II." Al respecto, la Conferencia Episcopal Peruana indica que «la fecundidad apostólica de los movimientos debe ser prudentemente encauzada para bien de toda la Iglesia en un diálogo entre sus dirigentes y el párroco y los colaboradores de las diversas pastorales de la parroquias, ${ }^{12}$ La motivación de fondo es elemental: es fâcil que un grupo con sus responsables que se mantienen en la informalidad in desarrolle actividades paralelas a las parroguias (Iglesias paralelas), actitudes contestatarias o conflictivas, o incluso que desmiembren la comunidad parroquial enrolando muchas veces los mejores elementos parroquiales para crear, así, la disgregación y la división de la comunidad. Porconsiguiente, en vista de lograr la comunión deseada enurc las comunidades, es necesario que la parroquia reconozca las asociaciones como un don del Espiritu, respetando su autonomía, y que las asociaciones reconozcan el papel central que le corresponde a la parroquia en la edificación de la Iglesia, ${ }^{\text {th }}$ sin permanecer como entes paralelos, con el objetivo de integrarse en la comunión para la realización de la misión eciesial.

Partiendo de los criterios de eclesialidad se pueden individualizar algunos criterios esenciales de eclesialidad de la ministerialidad odegética de los laicos, con particular atención hacia los responsables de los grupos, movimientos y asociaciones, Un ministerio odegético laical será eclesial si 
la comunidad a la que hace referencia es verdaderamente eclesial; si posee la voluntad firme de mantener la comunión con el obispo y sus representantes como garantía de ortodoxia y ortopraxis eclesial; si posee la capacidad de mantener el equilibrio entre la fidelidad a la Iglesia y la autonomía del grupo al que hacen referencia; si posee un auténtico espíritu eclesial y comunional que disponga al tesponsable a orientar las fuerzas del grupo hacia la comunión efectiva con la Iglesia local (diócesis o parroquia) y con las otras formas asociativas de los fieles en el territorio para trabajar juntos en la realización de la misión de la Iglesia.

A modo de conclusión, me parece importante cvidenciar que estas nuevas formas de ministerialidad de los laicos suscitadas hoy por el Espiritu en el ámbito odegético no parecen haber sido tomadas suficientemente en cuenta por el magisterio oficial de la Iglesia ni parecen haber encontrado todavía una situación ecuánime al interior de la organización eclesial, con las consecuentes dificultades para la actuación de una comunión eclesial efectiva. 


\section{Notas}

'Apostolicam actwositatem, $\mathrm{n}^{\circ} 18$.

'Secondin, B. uMovimenti e gruppi nella chiesas. En Ancilli, E. (ed.). Dizionario di spiritualitá deilaici. Milán: O. R., 1981, Pp. 68 y $71-72$.

'Estas últimas en la época de la primera evangelización del Nuevo Mundo.

"Comisión Episcopal de Apostolado Laical y Canferencia Episcopal Peruana. Asociacionesy movimientos eclesiales. Criterios de orientación. Lima: Siklos, 1996, pp. 8-30.

${ }^{5}$ Christifideles laici, n, 29.

"Ibidem.

${ }^{7}$ Cfr. Apostolicam actwositatem, n. ${ }^{\circ} 19$.

"Cfr. Christifideles laiti, n. ${ }^{\circ} 29$.

Juan Pablo II. uIncontro del Santo Padre con i movimenti ecciesiali e le nuove comunitả 30.05. 1998n. En Il Papa e i Movimenti, a cura del Pontijticio Consiglio per i Lnici. Milán: Edizioni San Paolo, 1998, p. 47.

${ }^{10} \mathrm{Cfr}$. Christifideles laici, $\mathrm{n}{ }^{\circ} 29$.

"Apostalicam actuositatem, $\mathrm{n},{ }^{\circ} 18$.

${ }^{12} J$ Jan Pablo II. aImpegno personale ed associativo nell'apostolato dei laici, Udienza generale 23, 03,1994\%, En Insegramenti di Giovanni Paolo 11, 17, 1 (1994). Cundad del Vaticano: Libreria Editrice Vaticana, 1996, p. 779.

13 Juan Pablo II. uApritevi con docilità ai doni dello Spiritow. En IIPapa e i Movimenti..., pp, 49-50.

${ }^{14} \mathrm{Cfr}$. Conferencia Episcopal Italiana, "Criteri di ecclesialità dei gruppi, movimenti, associazioniw (n, ${ }^{\circ}$ 6). ECEI, n. ${ }^{\circ} 3$, p. 592 .

"Beyer, J. Il rinnovamento del diritto e del laicafo nella chiesa. Milän: Editrice Áncora, 1993, p. 172.

${ }^{16} \mathrm{Cft}$. Cotignoli, C. «Movimento dei Focolariv. Orientamenti Pastorali, n. ${ }^{\circ} 46 / 4,1998$, pp. 40 -

45. «Alla guida vi è la Presidente, che per statuto sarà sempre una donna, láca, coadiuvata da un Consiglion, p. 42.

${ }^{17} \mathrm{Cfr}$. Comitato Nazionale di Servicio. aRinnovamento nello Spirito Santom. Orientamentz Pastorali, n. ${ }^{\circ} 46 / 4,1998$, pp. 46-49.

"Cfr. Gallo, A. vL'Équipes Notre-Damen. Orientamenti Pastorali, n. ${ }^{\circ} 46 / 4,1998$, pp. 55-62. 
${ }^{10} \mathrm{Cfr}$. Rieman, N. eLa animución en una comunidad responsabien. Las laicas tigy, n. ${ }^{\circ} 23-24$, 1977,pp. 162-163y 166.

Tbidem, pp. 168-173; Pouilly, $\Lambda$. Ministerialidad de los laicos en las tres vertientes de la pastorals, Medellin, n. ${ }^{\circ} 7,1981, \mathrm{p} .61$.

${ }^{21} \mathrm{Cfr}$, ibidem, p. 173.

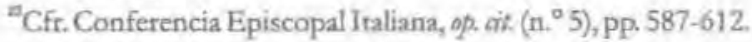

Apostolicaus actuositatem, n. $19 \mathrm{~d} ; \mathrm{cfr}$, tambièn n. ${ }^{\circ} 15$.

${ }^{2} \mathrm{Cft}$. Lumen gentium, $\mathrm{n} .{ }^{\circ} 33$; Apostolicam actuositatem, n. ${ }^{\circ} 3$.

${ }^{25}$ d. os sagrados Pastores han de reconocer la dignidad y la tesponsabilidad de los laicos en la Iglesia, Deben servirse de buena gana de sus prudentes consejos y encargarles con confianza algunas tareas al servicio de la Iglesia, dejándoles libertad y campo para actuar e incluso animarles para que también tomen iniciativas espontảneamentex, Lumen gentium, a, ${ }^{\circ} 37 \mathrm{c}$.

${ }^{30} \mathrm{Cfr}$. Apostolicam artwusilatem, n. ${ }^{\circ}$ 23-24.

${ }^{27}$ Cfr. Biffi, F. Prophet of Onr Mimes. The Social Thougbt of Candinal Pietro Pavan. Nueva Yotk: New City Press, 1992, pp. 112-113.

"Cfr. Apostolican actiositatem, n." 24 y $18 \mathrm{~b}$.

${ }^{\circ}$ Cfr. ibidem, n. $24 \mathrm{~d}$.

${ }^{*}$ Ibidem, n. ${ }^{\circ} 24 \mathrm{e}$,

"Evangelii nimtiandi, n. 73 .

${ }^{12}$ Cfr. Código de Derecho Canónieo, n. ${ }^{\circ} 317, \S 1 ;$ y 324, §1.

"Cfr, ibiden, n. ${ }^{\circ} 298,51$.

"Cfr. ibidem, n. 311 .

${ }^{15} \mathrm{Cfr}$, ibidem, n. ${ }^{\circ} 301, \$ 3$.

${ }^{36} \mathrm{Cfr}$ ibidem, n. $312, \$ 1$.

${ }^{31} \mathrm{Cfr}$. ibidem, n. 313.

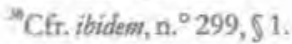

"Cfr ibiden, n. ${ }^{\circ} 298, \$ 1$.

${ }^{*}$ Cfr ibidem, n. $299, \$ 3$.

"Cfr, ibidem, n. ${ }^{\circ} 322, \$ 2$.

"Cfr, ibidem, n. ${ }^{\circ} 323$, @1.

${ }^{+1} \mathrm{Cfr}$ ibidem, n. ${ }^{\circ} 305, \S 1$.

"Cfr. ibidem, n. ${ }^{\circ} 317, \S 1$. 
${ }^{43} \mathrm{Cfr}$. ibidem, n. ${ }^{\circ} 321 ; 324 \rrbracket 1$.

${ }^{46} \mathrm{Cfr}$. Ibidem, n. ${ }^{\circ} 324, \$ 2$.

"Ibidem, n. 328.

"Ibidem, n. 329.

${ }^{49} \mathrm{Cfr}$. Beyer, J, op. it., pp. 167-168.

${ }^{50}$ Christifideles laici, n. ${ }^{0} 29,30$ y 31 .

${ }^{51} 1$ bidem, n. ${ }^{\circ} 29$,

${ }^{52}$ Ibidem.

${ }^{35} \mathrm{Cfr}$. Redemptoris missio, n. ${ }^{0}$ 73-74.

${ }^{54} \mathrm{Cft}$, ibidem, $\mathrm{n}^{0}{ }^{071-72 .}$

${ }^{55} \mathrm{Cft}$. ibidem, n. ${ }^{0} 72$.

${ }^{56} \mathrm{Cfr}$. Lumen gentium, n. ${ }^{\circ}$ 31-36; Presbiterorum Ordinis, $\mathrm{n} .{ }^{\circ}$ 4-6.

st Apostolicam actuositatem, n. ${ }^{\circ} 2$.

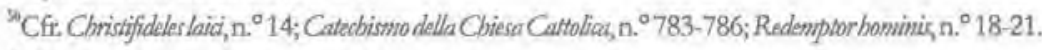

${ }^{59}$ Código de Derecho Canónico, n. ${ }^{\circ} 204$.

${ }^{60}$ Cfr. Calero, A. El laico en la Iglesia. Vocacióny misión. Madrid: CCS, 1998, pp. 87-128; Malnati, E. Teologia del laicato. Alessandria: PIEMME, 2000, pp. 39-53; Montan, A. Uncarichi, uffici, ministeri laicali nelle comunità ecclesiali: parrocchie, unità pastorali, diocesì. En Ciola, N. (ed.). Servine ecclesine. Miscellanea in onore di Mons. Pino Scabini. Bolonia: Edizioni Dehoniane Bologna, 1998, pp. 571-572.

${ }^{51}$ Cfr. Brandolini, L. Ministeri e senvizi nella Cbiesa di oggi. Roma: Centro Liturgico Vincenziano, 1992, pp. 48-57.

${ }^{62} \mathrm{Cfr}$, Midali, M. Teologia prática 1. Cammino storico di una niflessione fondante e cientifica. Roma: LAS, 2000, pp. 387-389; Manzanares Marịuan, J «Vocación y misión de los laicos dentro de la relación "Iglesia-mundo"s. En Chicas, F. el al (eds.). Erclesia Tertii millentiii advenientis. Alessandria: PIEMME, 1997, pp, 793-794; Blázquez, R. I a Iglesio del Conoilio Vationo II. Salamanca: Sígueme, 1988 , p. 376; Borobio, D. Los ministerios en la comunidad. Barcelona: Centro de Pastoral Litúrgica, 1999, pp. 83-84,

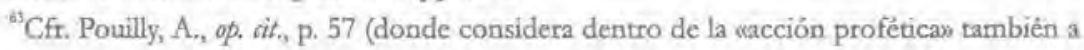
algunos uresponsables laicos de movimientosn); Pertot, C. «La epístola a los Hebreosi. En Delorme, J. (ed.). El ministerio y los ministerios según el Nuevo Testamento. Madrid: Ediciones Cristiandad, 1975,pp. 130-131. 
${ }^{4}$ Cfr. Midali, M., op. cit., pp. 387-388.

${ }^{65}$ Pouilly, A, op. at, , PP, 58-59.

"Borobio, D., op. cit., p. 84; cfr. tambiên pp. 33 y 46.

${ }^{5 /}$ Ibidem, p. 84.

${ }^{68}$ Cfr. Giglioni, P. Carismi e ministeri per sna pastorale missionaria. Roma: Urbaniana University Press, 1996, p. 27; Sartori, L, «Carismi e ministerin, En Dizionstro leologico Iniendisciplinare. Vol.

I. Turin: Marietti, 1977, pp. 504-516.

${ }^{69} \mathrm{Cfr}$. Lamen gentium, $\mathrm{n}^{\circ} 35$,

${ }^{70}$ Pueden ser desempeñados también por teligiosos, religiosas o sacerdotes.

${ }^{71}$ C.fr. Giglioni, P., op. cit., p. 30; Rzepkowski, H. «Chiesa localen. En Lessico di missiologia. Storia Teologia Emologia. Ciudad del Vaticano: Libreria Editrice Vaticana, 2000, pp. 143-145.

${ }^{72}$ Coccopalmerio, F. La parroccbia. Tra Concilio Vaticano II e Codice di diritto canomico. Milán: San Paolo, 2000, p. 65. El concilio na define la parroquia. El Código de Derecho Canónico de 1983 (n. 515, \& 1) ha definido la parroquia como una commutias shristifideliam (comunidad de fieles). Los elementos eclesiológicos fundamentalmente determinantes de la parroquia como comunidad según el Código de Derecho Canónico son dos: el principio comunitario y el principio jerárquico; cfr. Montan, A. uI soggetti dell'azione pastorale nella comunità parrocchialen. En Ciola, N. La Parroctbia in un 'ectlesiologia di comsnione. Bolonia: Edizioni Dehoniane Bologna, 1995, p. 162.

${ }^{73}$ Cfr. Borras, A, La parrocchia. Dinitso canonico e prospeltive pastorati. Bolonia: Edizioni Dehoniane Bologna, 1997, p. 218.

${ }^{74} \mathrm{Cfr}$ ibidem, pp. 218-219.

${ }^{75} \mathrm{Cfr}$. Lumen gentium, n. ${ }^{\circ} 23$; Sacrosanctum Concilisum, n. ${ }^{\circ} 43$; Christifideles laici, n. ${ }^{\circ} 25$; Chrisfus Damnus, n. ${ }^{\circ} 11$.

${ }^{76}$ Cfr. Borras, A., op. cit., p. 254.

${ }^{\pi}$ Cfri ibidem, p. 219.

${ }^{7 *} \mathrm{Cfr}$. Forte, B. aAssociazioni, movimenti e missione nella chiesa localew. Il mgno documenti, n. ${ }^{\circ} 28,1983$, pp. 33-34.

${ }^{79}$ Cfr. Borras, A. op, cit., p. 219.

${ }^{6} \mathrm{Cfr}$. Evangelii numtiandi, n, ${ }^{\circ} 58$; Chrzstifideles laid, n, ${ }^{\circ} 30$.

${ }^{\text {gi }} \mathrm{Cfr}$. Antioquia, Ignacio de aAgli smimeși. En Bosio, G. Iniziazione ai Padri. Vol. I. Turin: Societa Editrice Internazionale, 1964,p. 74: „Dove appare il vescovo, ivi è la comunitả, come dov'è Gesủ Cristo, iviè ls Chiesa Cattolican. 
"Cfr. Coccopalmerio, F., op, cit., pp, 65-66,

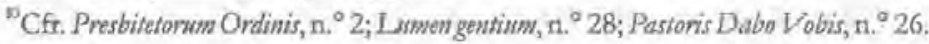

${ }^{M}$ Cft. Kasper, W. «noovi accenti nella concezione dogmatica del ministero sacerdotale». Concilium, n. ${ }^{\circ} 5,1969$, p. 249.

${ }^{15}$ Catechismo della Chiesa Cattolica, n. 1552.

"BitBorobio, D., op. cit., p.221.

"«cclesialitá, infatti, è termine esigente: significa saper di appartenere alla Chiesa e, più ancora, saper di "essere Chiesa" e aver il "senso della Chiesa" aggregazioni laicali nella chiesa) (n. $\left.{ }^{\circ} 12\right) \cdot E C E I, n .{ }^{0} 5, \mathrm{p}, 1568$.

${ }^{24} Y_{a}$ Pablo VI, en la Evangelii nuntiandi n. ${ }^{\circ} 58$, habla de algunos criterios de discernimiento aplicados a las comunidades eclesiales de base que quisieran llamarse verdaderamente eclesiales, pero válidos también para otros grupos eclesiales. Podemos resumirlos así: se alimentan de la Palabra de Dios sin dejarse manipular por la politica o por ideologias; evitan la scontestación sistemática y el espiritu hipercríticon; mantienen la unidad con la iglesia local y universal; guardan la comunión sincera con los legitimos pastores y con su magisterio; aceptan la legítima diversidad de formas eclesiales; no se consideran «el único depositario del evangeliow; crecen en misionariedad; se muestran universales y no sectarias. Posteriormente, la Comunidad Episcopal Itliana (CEI), por vez primera, interviene sistematicamente can la nota pastoral «Criteri di ecclesialità dei gruppi, movimenti, associazionin (1981). Esta terminología pasa a la Iglesia Universal con la Christifideles laici, n. ${ }^{\circ} 30$, que propone sintéticamente algunos "criterios de eclesialidad", retomándolos de la Proposition, $n{ }^{\circ} 16$, del Sínodo de los Obispos del 87. La nota pastoral Le aggregzarioni laicali nella chiesa de 1993 de la CEI ha retomado el tema de los eriterios de eclesialidad de los grupos, movimientos y asociaciones, y las condiciones para su reconocimiento Cfr. Castellano Cervera, J. «I movimenti ecclesiali, criteri di discernimentom. En Ciola, N. (ed.), op.cit., pp. 612-613.

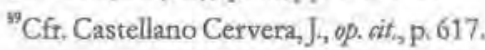

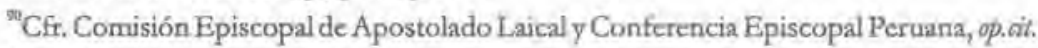

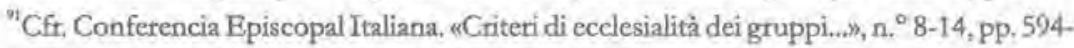
600; Conferencia Episcopal Española y Comisión Episcopal de Pastoral. Servicia Pastoral a lus pequeñas comtnidades cristianas (15 de marzo de 1982). Madrid: Editorial de la Conferencia Episcopal Española, 1982. Repropone en el n. ${ }^{\circ} 10$ los criterios de la Evangelii nutitiandin n. ${ }^{\circ} 58$ y ofrece algunos elementos útiles para una evaluación por parte de las communidades o desde fuera, por parte de los obispos, vicarios de pastoral uotros ministros de pastoral: cfr. n. ${ }^{\circ} 11-$ 
31; National Conference of Catholic Bishops and Committee on the Laity. Called and gifted for the third millennium, November 1995. Washington D. C.: United States Catholic Conference, 1994, p. 12: se explicita las caracteristicas de las auténticas «small christian communities». " "El problema, sin embargo, no es tanto la determinación de unos elementos de identidad, cuanto el discernimiento sobre su real verificación práctica en los diversos "niveles" o situaciones comunitarias de realización de la Iglesia: Diócesis, parroquia, comunidades "personales", (de emigrantes, estudiantes, heterogénea), cornunidades de base, comunidades religiosas, gnupos menores de comunidadb. Borobio, D. Los ministerios en la comunidad. Barcelona; Centre de Pastoral Litúrgica, 1999,p. 101.

"Cfr. Castellano Cervera, J., op. cit., p. 609; Beyer, J., op. sit., p. 169.

${ }^{94}$ Cbristifideles laici, n. ${ }^{\circ} 30$.

${ }^{95} \mathrm{Cfr}$. ibridem.

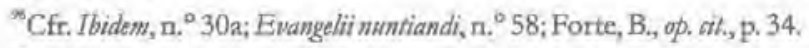

"uove appate il vescovo, ivi è la comunità, come dov"è Gesù Cristo, ivi è la Chiesa cartolica». Antioquia, Ignacio dc, op. cit., p. 74.

"Christifideles laici, n. 31.

5Juan Pablo II, «Impegno personale ed associativo...., p. 779.

${ }^{100}$ Cfr. Rieman, N., op. cit., p. 163.

${ }^{100}{ }^{\mathrm{A}} \mathrm{E}$ ' insomma necessario che si ponga in atto un processo di reciproca e feconda recezionc dei movimenti e delle associazioni, col loro specifico irrinunciabile, e della Chiesa locale, in tutta la ricchezza delle sue espressioni carismariche e ministerialis. Forte, B. op. cit., p. 34; cfr. también Redempsor missio, n. 72.

${ }^{102}$ Cfr. Rieman, N., op. cit., p. 170.

${ }^{10 s} \mathrm{Cfr}$. Montan, A., «I soggetti dell'azione pastorale nella comunitì parrocchiales, p. 179.

"Véase, por ejemplo, wineamenta. Vocazione e missione dei laici aella Chiesa enel mondo" (n. $\left.{ }^{\circ} 37\right), E V, n^{\circ}{ }^{\circ}$, p, 1393; cfr. Scatizzi, S: «Norme per i rapporti fra movimenti e comunita parrocchialiw. Orientamenti Pastorali, n. ${ }^{\circ} 46,1998$, pp. 76-81.

${ }^{105}$ Marcandalli, G. WNon estinguere lo Spirito, Movimentie Chiesa locales, Orientamenti Pastorali, n. 46,1998 , pp. $72-73$.

${ }^{100} \mathrm{Cfr}$. ibident, p. 74.

${ }^{701}$ Christifideles laici, $\mathrm{n}^{\circ}{ }^{3} 31$.

${ }^{108} \mathrm{Cfr}$. Juan Pablo II, 《Impegno personale ed associativow, pp. 780 y 782. 
${ }^{167}$ Christifideles laici, n. ${ }^{\circ} 31$.

${ }^{150}$ Parra, A. aMinisterios desdela Iglesia de América Latina». Cuademas de Teologia, n. ${ }^{\circ}$ 5, 1982, p. 33.

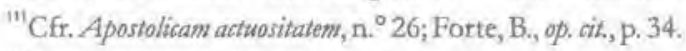

${ }^{12}$ Comisión Episcopal de Apostolado Laical y Conferencia Episcopal Peruana, op. cit., p. 78.

${ }^{113} \mathrm{Cft}$. Pérez Guadalupe, J. L. Ecomenismo, sectas y nuevos movimientos religiosos. Lima: Asociación Hijas de San Pablo, 2002, pp. 399-413 (sobre la «informalidad eclesial»).

${ }^{114} \mathrm{Cfr}$. Montan, A., «d soggetti dell'azione pastorale nella comunita parrocchiale», p. 179. 